\title{
Bacterial Foraging Algorithm based Enhancement of Voltage Profile and Minimization of Losses Using Thyristor Controlled Series Capacitor (TCSC)
}

\author{
M.Senthil Kumar \\ Assistant Professor/EEE \\ Sona College of Technology, \\ Salem, Tamilnadu, India
}

\author{
Dr.P.Renuga \\ Assistant Professor/EEE \\ Thiagarajar College of Engineering, \\ Madurai, Tamilnadu, India
}

\begin{abstract}
Loss minimization in power system is an important research issue. Transmission line losses in a power system can be minimized by means of reactive power compensation. The continuous demand in electric power system network has caused it to be heavily loaded leading to voltage instability. This phenomenon has also led to voltage profile depreciation below the acceptable secure limit. The significance and use of Flexible AC Transmission Systems (FACTS) devices and capacitor placement is in order to alleviate the voltage profile decay problem. Identification of the optimal value of compensating devices requires proper optimization technique, easy to search the optimal solution with less computational burden. This paper presents an application of Bacterial Foraging (BF) algorithm in optimizing the optimal location and design of Thyristor Controlled Series Capacitor (TCSC) for voltage profile improvement and minimization of losses in a power system which utilized the TCSC as the control variable. The proposed approach has been evaluated with three different objective functions namely, loss minimization, voltage profile improvement and voltage stability enhancement. Voltage stability level of the system is defined on the L-index of the load buses. The IEEE 14bus and IEEE 30bus systems are used as test systems to demonstrate the applicability and efficiency of the proposed system. The proposed method is compared with Genetic Algorithms (GAs) and Non-dominated Sorting Particle Swarm Optimization (NSPSO). The test result shows that the location of TCSC improves the voltage profile of the system and also minimizes the transmission line losses.
\end{abstract}

Keywords - Flexible AC Transmission Systems (FACTS), Thyristor Controlled Series Capacitor (TCSC), Multi-Objective function, Bacterial Foraging (BF), L-index.

\section{INTRODUCTION}

Most large power system blackouts, which occurred worldwide over the last twenty years, are caused by heavily stressed system with large amount of real and reactive power demand and low voltage condition. When the voltages at the system buses are low, the losses will also be increased. This study is devoted to develop a technique for improving the voltage and minimizing the losses and hence eliminate voltage instability in a power system [1]. Many techniques of compensation were used by power system industries to minimize the losses and improve the voltage profile, such as on-load tap changing (OLTC) transformer and Flexible AC Transmission Systems (FACTS) devices. Introducing FACTS controller at the appropriate location is the most effective way to improve the voltage and power flow in many utilities [2], [8], [11], [13]. Static Var Compensator (SVC), Thyristor Controlled Phase Shifting Transformer (TCPST) and Thyristor Controlled
Series Capacitor (TCSC) can exert a voltage in series with the line and, therefore, can control the active power through a transmission line [2],[11]. In this study TCSC is considered as a control device and it has several advantages which include:

- increase in maximum power that can be transmitted on a line.

- $\quad$ reduced line reactance

- $\quad$ improved power system stability

- improved voltage regulation of transmission line

Many advantages in power system operation and planning can be immediately realized by regulating the power flows and simultaneously supporting the bus voltages. Such advantages include the minimization of system losses, elimination of line overloads and low voltage profiles. Recently, the Evolutionary Computation (EC) in the solution of complex problems such as Differential Evolution (DE) [3], Particle Swarm Optimization (PSO) [4], Ant Colony Optimization (ACO), and Genetic Algorithms (GAs) are some of the heuristic techniques having great convergence characteristics and capability of determining global optima. F.G.Bagriyanik et.al [5] proposed a technique for power loss minimization based on Genetic Algorithm using TCSC. R.Benabid and M.Boudour [6] proposed an application of NSPSO to solve the optimal location and size of SVC and TCSC for voltage stability enhancement. This paper, proposes a method for finding the optimal location and design of Thyristor Controlled Series Capacitor (TCSC) using Bacterial Foraging algorithm in order to minimize the real power loss, voltage profile improvement and voltage stability enhancement. The voltage stability assessment is analyzed using L-index approach. L-index gives a scalar number to each load bus. This index ranges from zero (no load system) to one (voltage collapse). Thus the bus with the highest L-index value will be vulnerable bus in the system and hence this method helps in identifying the weak load buses in the system which needs critical reactive power support. This paper uses minimization of L-index of the system as one of the objectives of the optimization problem.

The Bacterial Foraging algorithm is a computational intelligence based technique that is not largely affected by the size and nonlinearity of the problem and can converge to the optimal solution in many problems where most analytical methods fail to converge. The bacterial foraging based L-index is calculated in each step after performing Newton-Raphson (N-R) load flow study. The BF based L-index clearly indicates the location and status of critical bus bar. The proposed algorithm has been tested on IEEE 14-bus and IEEE 30-bus reliability test systems. A load flow program written in MATLAB using bacterial foraging technique was used to compute power flow. The performance of the proposed algorithm is compared with Genetic Algorithms and Non-dominated Sorting Particle Swarm Optimization. The test 
results show that the location and sizing of the TCSC identified by the proposed technique improves voltage level of the system and also minimize the losses. For practical and economic considerations, the number of TCSC units is limited to one [14]. Here TCSC is connected in between buses 9 and 14 in IEEE 14bus system and buses 29 and 30 in IEEE 30- bus system to perform the test.

This paper is organized as follows: Model of TCSC is given in section 2. Problem Formulation is given in section 3. Bacterial Foraging algorithm for proposed method is given in section 4 . Results and discussion are given in section 5, the conclusion is drawn in section 6 and References are given in section 7 .

\section{MODEL OF THYRISTOR CONTROLLED SERIES CAPACITOR (TCSC)}

Thyristor Controlled Series Capacitor (TCSC) is a series compensation component which consists of capacitor bank shunted by Thyristor Controlled Reactor (TCR). The basic idea behind power flow control with TCSC is to decrease or increase the overall effective impedance of the transmission line, by adding a capacitive or inductive reactance correspondingly. The TCSC is modeled as a variable impedance, where the equivalent reactance of the line $X_{\mathrm{ij}}$ is defined as

$X_{i j}=X_{\text {line }}+X_{T C S C}$

Where, $X_{\text {line }}$ is the transmission line reactance, and $X_{\text {TCSC }}$ is the TCSC reactance. The level of the applied compensation of the TCSC usually varies between $20 \%$ inductive and $80 \%$ capacitive [6].

\section{PROBLEM FORMULATION}

The objective function of this paper is to find the optimal rating and design of TCSC which minimizes the real power loss, voltage deviation and L-index. This is mathematically stated as [9], [13]: Minimize

$\mathrm{F}=\left[f_{1}, f_{2}, f_{3}\right]$

The first term $\mathrm{f}_{1}$ represents real power loss as [9, [13]

$f_{1}=\sum_{k \in N l} g_{k}\left(V_{i}^{2}+V_{j}^{2}-2 V_{i} V_{j} \cos \theta_{i j}\right)=P_{\text {loss }}{ }^{l}$

The second term $\mathrm{f}_{2}$ represents the total voltage deviation (VD) of all load buses from desired value of 1 p.u.

$$
f_{2}=V D=\sum_{k=1}^{N_{P Q}}\left(V_{k}-\operatorname{Vref}_{k}\right)^{2}
$$

The last term $f_{3}$ is the L-index of the $j^{\text {th }}$ bus and is given by

$$
f_{3}=L_{j}=\left|1+\frac{V_{\mathrm{O} j}}{V_{j}}\right|=\frac{S_{j}^{+}}{Y_{j j} V_{j}^{2}}
$$

$S^{+}{ }_{j}=$ Complex power at $j^{\text {th }}$ node

$V_{j}=$ Voltage at $j^{\text {th }}$ node
$Y_{j j}=$ Admittance from bus admittance matrix

The minimization problem is subject to the following equality and inequality Constraints:

(i)Load Flow Constraints

$$
\begin{aligned}
& P_{i}-V_{i} \sum_{j=1}^{N g} V_{j}\left(G_{i j} \cos \theta_{i j}+B_{i j} \sin \theta_{i j}\right)=0, i=1,2, \ldots \ldots N_{B}-1 \\
& Q_{i}-V_{i} \sum V_{j}\left(G_{i j} \sin \theta_{i j}-B_{i j} \cos \theta_{i j}\right)=0, i=1,2, \ldots . N_{P Q}-1
\end{aligned}
$$

(ii) Voltage Constraints:

$$
V_{i}^{\mathrm{min}} \leq V_{i} \leq V_{i}^{\mathrm{max}} ; i \in N_{B}
$$

(iii) Reactive Power Generation Limit:

$$
Q_{g i}^{\min } \leq Q_{g i} \leq Q_{g i}^{\max } ; i \in N_{g}
$$

(iv) Reactive Power Generation Limit of capacitor banks:

$$
Q_{c i}^{\mathrm{min}} \leq Q_{c i} \leq Q_{c i}^{\max } ; i \in N_{c}
$$

(v) Transformer tap setting limit:

$$
t_{k}^{\text {min }} \leq t_{k} \leq t_{k}^{\max } ; k \in N_{t}
$$

(vi) Transmission line flow limit:

$$
S_{i} \leq S_{i}^{\max } ; i \in N_{l}
$$

\section{BACTERIAL FORAGING ALGORITHM FOR THE PROPOSED METHOD}

Foraging theory is based on the assumption that animals search for nutrients which maximizes their energy intake (E) per unit time (T) spent for foraging [7]. The E.coli bacterium is probably the best understood micro organism. Mutation in E.coli occurs at a rate of about $10^{-7}$ per gene, per generation and can affect its physiological aspects. The E.coli bacterium has a control system that enables it to search for food and avoid noxious substance. To find the minimum of $J, \theta \in R^{p}$ where there is no measurements or analytical description of the gradient $\nabla J \boldsymbol{\theta}$. $\theta$ is the position of a bacterium and $J \boldsymbol{\theta}^{-}$represents the combined effects of attractants and repellents from the environment, for example $J \boldsymbol{\theta}_{-}^{-}, J \boldsymbol{\theta}_{-}^{-}$and $J \boldsymbol{\theta}_{-}^{-}$ representing that the bacterium at location $\theta$ is nutrient-rich, neutral and noxious environments respectively.

Basically chemotaxis is a foraging behavior that implements a type of optimization where bacteria try to climb up to the nutrient concentration, avoid noxious substance and search for ways out of neutral media. It implements a type of biased random walk which define a chemotactic step, be a tumble followed by another tumble or by a run.

Let $j$ be the index for the chemotactic step, $k$ be the index for the reproduction step and $l$ be the index of the eliminationdispersal event.

Let $P \boldsymbol{4}, k, l=\theta^{i} \mathbf{4}, k, l \underline{i}=1,2, \ldots . S$ 
The equation (13) represents the position of each member in the population of the $\mathrm{S}$ bacteria, at the $j^{\text {th }}$ chemotactic step, $k^{\text {th }}$ reproduction step and $l^{\text {th }}$ elimination-dispersal event.

Let $\mathrm{N}_{\mathrm{c}}$ be the length of the life time of the bacteria as measured by the number of chemotactic steps taken during their life. Let $C>0, i=1,2, \ldots . \mathrm{S}$ denotes a basic chemotactic step size, that is used to define the lengths of steps during runs. To represent a tumble, the unit length random direction say $\phi$ generated. This will be used to define the direction of movement after a tumble. This swim is continued as long as it continues to reduce the loss, but only upto a maximum number of steps, $\mathrm{N}_{\mathrm{s}}$. This represents that the cell will tend to keep moving if it is headed in the direction of increasingly favorable environments. After $\mathrm{N}_{\mathrm{c}}$ chemotactic steps, a reproduction step is taken.

Let $\mathrm{N}_{\mathrm{re}}$ be the number of reproduction steps to be taken. For reproduction the population is sorted in order that the least healthy bacteria die and the healthiest bacteria each split into two bacteria which are placed at the same location. This method rewards bacteria that have encountered a lot of nutrients and this allows it to keep a constant population size which is convenient in coding the algorithm.

Let $\mathrm{N}_{\mathrm{ed}}$ be the number of elimination-dispersal events and for each elimination-dispersal event each bacterium in the population is subject to elimination-dispersal with probability $\mathrm{P}_{\text {ed }}$. Assume that the frequency of chemotactic steps is greater than the frequency of reproduction steps, which is in turn greater in frequency than elimination-dispersal events.

\subsection{Algorithm}

Step 1 Initialize the parameters $\mathrm{p}, \mathrm{S}, \mathrm{N}_{\mathrm{c}}, \mathrm{N}_{\mathrm{s}}, \mathrm{N}_{\mathrm{re}}, \mathrm{N}_{\mathrm{ed}}, \mathrm{P}_{\mathrm{ed}}$ and the

$\mathrm{C}(i),(i=1,2, \ldots \ldots, \mathrm{S})$. Choose the initial value for the $\theta^{i}$ $, i=1,2 \ldots$. S. These must be done in areas where an optimum value is likely to exist. Here $\theta$ is the control and is randomly distributed across the domain of the optimization space. After computation of $\theta$ is completed, the value of $\mathrm{P}$ is updated automatically and termination test is done for maximum number of specified iterations.

Step 2 Elimination-Dispersal loop: $l=l+1$

Step 3 Reproduction loop: $k=k+1$

Step 4 Chemotaxis loop: $j=j+1$

(i) For $i=1,2, \ldots, \mathrm{S}$ take a chemotactic step for bacterium ' $\mathrm{i}$ ' as follows:

(ii) Compute $J(i, j, k, l)$.

(iii) Let $J(i, j, k, l)=J(i, j, k, l)+J_{c c}\left(\theta^{i}(j, k, l), \mathrm{P}(j, k, l)\right)$

(iv) Let $J_{\text {last }}=J(i, j, k, l)$ to save this value since find better solution via a run

(v) Tumble: Generate a random vector $\Delta \dot{\Delta} \in R^{p}$
With each element $\Delta_{m}$ random number

(vi) Move let $\theta^{i}(j+1, k, l)=\theta^{i}(j, k, l)+\mathrm{C}(i) \frac{\Delta(i)}{\sqrt{\Delta^{T}(i) \Delta(i)}}$ This results in a step of size $\mathrm{C}(i)$ in a direction of the tumble for bacterium $i$

(vii) Compute $J(i, j+l, k, l)$.

The load flow analysis using N-R method is carried out. The values of L-index and real power loss are calculated. If the loss is minimum then next step can be carried out else go to step (iii)

(viii) Swim.

(a) Let $\mathrm{m}=0$ (counter for swim length)

(b) While $\mathrm{m}<\mathrm{N}_{\mathrm{s}}$ Let $\mathrm{m}=\mathrm{m}+1$

If $J(i, j+1, k, l)<J_{\text {last }}$ (if there is improvement), let $J_{\text {last }}=J(i, j+1, k, l)$ and

let $\theta^{i}(j+1, k, l)=\theta^{i}(j+1, k, l)+\mathrm{C}(i) \frac{\Delta(i)}{\sqrt{\Delta^{T}(i) \Delta(i)}}$ and use

this $\theta^{i}(j+l, k, l)$ to compute the new $J(i, j+l, k, l)$.

Else, let $\mathrm{m}=\mathrm{N}_{\mathrm{s} .}$. End of while statement

(ix) Go to next bacterium $(i+1)$ if $i \neq \mathrm{S}$

Step 5 If $j<\mathrm{N}_{\mathrm{c}}$ go to step 3 . In this case, continue chemotaxis, Since the life of the bacteria is not over.

Step 6 Reproduction

(a) For the given $\mathrm{k}$ and $l$, and for each $i=1,2, \ldots, \mathrm{S}$, let

$$
J_{\text {health }}^{i}=\sum_{j=1}^{N c+1} J j, k, l^{-}
$$

be the health of bacterium i. Sort bacteria and chemotactic parameter $\mathrm{C}(i)$ in order of ascending value of $J_{\text {health }}$

(b) The $S_{\mathrm{r}}$ bacterium with the highest $J_{\text {health }}$ values die and the other $S_{\mathrm{r}}$ bacteria with the best values split.

Step 7 If $\mathrm{k}<\mathrm{N}_{\mathrm{re}}$, go to step 2. In this case we have not reached the number of specified reproduction steps.

Step 8 Elimination-Dispersal For $i=1,2, \ldots ., \mathrm{S}$ with probability $\mathrm{P}_{\mathrm{ed}}$, eliminate and disperse each bacterium. Eliminate a bacterium and disperse one to a random location on the optimization domain. If $l<\mathrm{N}_{\mathrm{ed}}$, then go to step 1 , otherwise end.

The L-index, real power loss and bus voltages are also obtained separately. The flowchart for the proposed algorithm is shown in fig1.The parameter of the bacterial foraging algorithm is given in table 1 . 

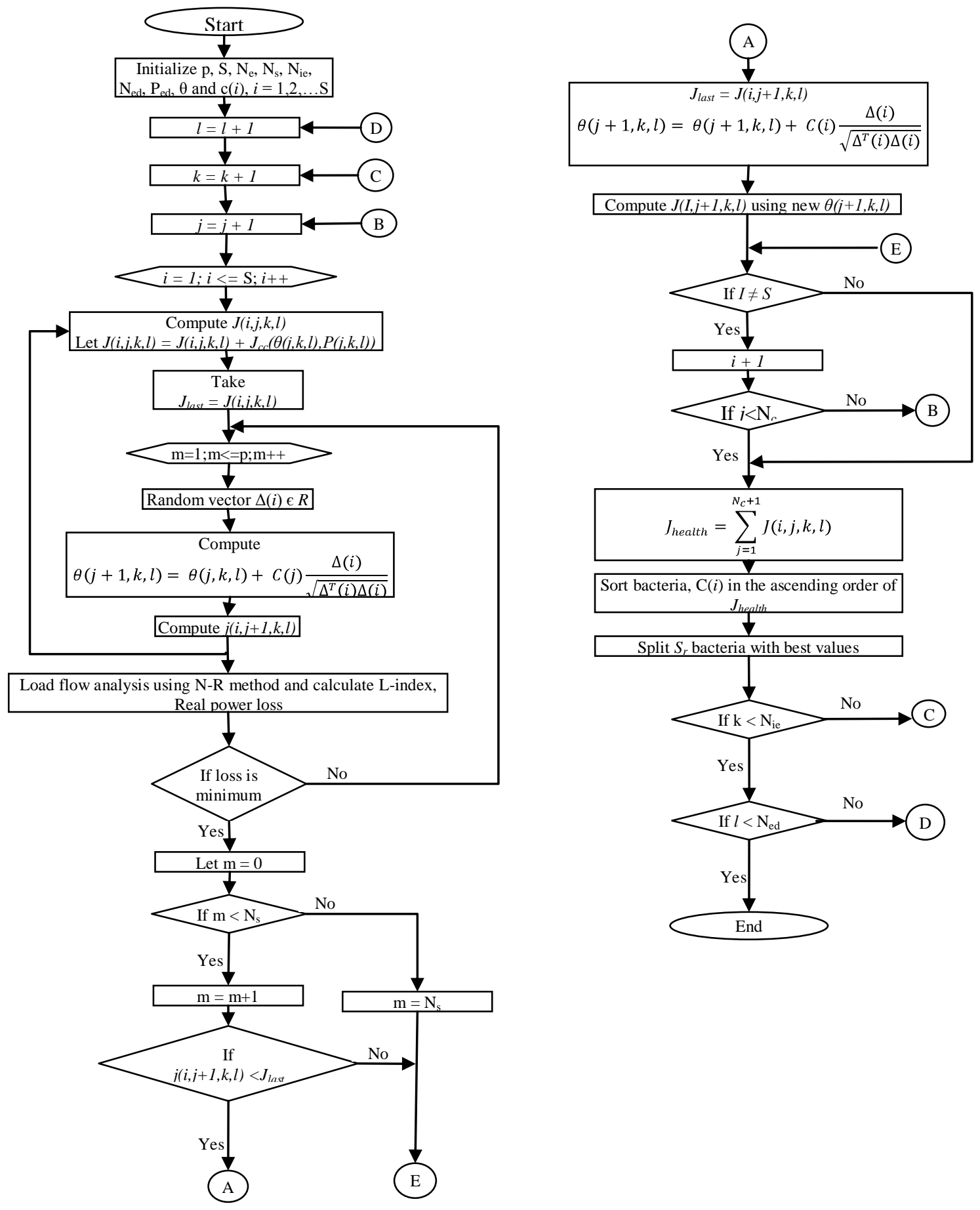

Figure 1. Flowchart for the Bacterial Foraging Algorithm 
Table 1. Control parameters of the bacterial foraging algorithm [7]

\begin{tabular}{|c|l|c|}
\hline $\begin{array}{c}\text { Sl. } \\
\text { No }\end{array}$ & \multicolumn{1}{|c|}{ Parameters } & Values \\
\hline 1 & Number of bacteria ,S & 50 \\
\hline 2 & Maximum number of steps, $\mathrm{N}_{\mathrm{s}}$ & 4 \\
\hline 3 & Number of chemotactic steps, $\mathrm{N}_{\mathrm{c}}$ & 100 \\
\hline 4 & ${\text { Number of reproduction steps, } \mathrm{N}_{\mathrm{re}}}$ & 4 \\
\hline 5 & ${\text { Number of elimination-disperse steps, } \mathrm{N}_{\mathrm{ed}}}$ & 2 \\
\hline 6 & Probability, $\mathrm{P}_{\mathrm{ed}}$ & 0.25 \\
\hline 7 & Size of the step, C(i) & 0.1 \\
\hline
\end{tabular}

\section{RESULTS AND DISCUSSION}

The program for the Bacterial Foraging based optimization algorithm used in this study was written in MATLAB 7.0 on Pentium IV, 3GHz,512 MB RAM processor and used to perform the optimization routines with IEEE 14-bus and IEEE 30-bus systems. System data and results are based on 100 MVA and bus1 is the reference bus. In order to verify the presented models and illustrate the impacts of TCSC study, three cases for test systems are considered.

Case-1: results of optimal power flow without TCSC

Case-2: results of optimal power flow with one TCSC for the base case (i.e light load)

Case-3: results of optimal power flow with one TCSC for the critical case (i.e heavy load-whose loads and initial power generations are twice as those case of 2)

The aim of case- 2 and 3 are minimized losses with optimal placement of TCSC between weakest load buses. For practical and economic considerations, the number of TCSC units is limited to one [14]. The impedance of line with TCSC (0.0422p.u) is connected between buses 9 and 14 (in IEEE 14-bus system), and the impedance of line with TCSC $(0.1575$ p.u $)$ is connected between buses 29 and 30 (in IEEE 30 bus system) to perform the test. The IEEE 14-bus system, which consists of five generator buses, 9 load buses and 20 lines in which three lines are with the tap changing transformers. The line parameters and loads are taken from [13]. IEEE 30- bus system comprises of 6 generator buses, 24 load buses and 41 lines of which 4 branches are with the tap changing transformers. The transmission line parameters and the loads are taken from [4]. Table 2 gives the control variables for the two test systems.

Table 2. Control variables for IEEE 14-bus \& IEEE 30-bus Systems

\begin{tabular}{|c|l|c|c|}
\hline Test cases & Variables & $\begin{array}{c}\text { Minimum } \\
(\mathbf{p . u})\end{array}$ & $\begin{array}{c}\text { Maximum } \\
(\mathbf{p . u})\end{array}$ \\
\hline $\begin{array}{c}14 \text { bus and } \\
30 \text { bus } \\
\text { systems }\end{array}$ & Voltage & 0.95 & 1.10 \\
\cline { 2 - 4 } & Tap setting & 0.90 & 1.10 \\
\cline { 2 - 4 } & $\mathrm{X}_{\mathrm{TCSC}}$ & $-0.8 \mathrm{X}_{\text {line }}$ & $0.2 \mathrm{X}_{\text {line }}$ \\
\hline
\end{tabular}

Table 3 and 4 show the state variables of IEEE 14-bus and IEEE 30-bus systems. Table 5 and 6 gives the loss values of proposed method and Fig 2 shows the voltage variations of IEEE 14-bus system without and with TCSC. From the fig 2 it is clear that the voltage dips are reduced effectively with the proposed method.

Table 3. State variables of IEEE 14-bus system

\begin{tabular}{|c|c|c|c|c|c|c|}
\hline \multirow{2}{*}{$\begin{array}{c}\text { Bus } \\
\text { no }\end{array}$} & \multicolumn{2}{|c|}{$\begin{array}{c}\text { Case-1 } \\
\text { (Without TCSC) }\end{array}$} & \multicolumn{2}{c|}{$\begin{array}{c}\text { Case-2 } \\
\text { (With TCSC base } \\
\text { load) }\end{array}$} & \multicolumn{2}{c|}{$\begin{array}{c}\text { Case-3 } \\
\text { With TCSC } \\
\text { critical load) }\end{array}$} \\
\cline { 2 - 7 } & L-index & Voltage & L-index & Voltage & L-index & Voltage \\
\hline 4 & 0.0115 & 1.0239 & 0.0115 & 1.0261 & 0.0243 & 0.9946 \\
\hline 5 & 0.0020 & 1.0314 & 0.0020 & 1.0329 & 0.0420 & 1.0015 \\
\hline 7 & 0.0000 & 1.0438 & 0.0000 & 1.0438 & 0.0000 & 1.0438 \\
\hline 9 & 0.0129 & 1.0267 & 0.0077 & 1.0411 & 0.0156 & 1.0272 \\
\hline 10 & 0.0064 & 1.0268 & 0.0042 & 1.0391 & 0.0076 & 1.0239 \\
\hline 11 & 0.0039 & 1.0445 & 0.0038 & 1.0509 & 0.0071 & 1.0413 \\
\hline 12 & 0.0084 & 1.0523 & 0.0084 & 1.0529 & 0.0168 & 1.0332 \\
\hline 13 & 0.0106 & 1.0460 & 0.0077 & 1.0460 & 0.0142 & 1.0177 \\
\hline 14 & 0.0256 & 1.0169 & 0.0098 & 1.0355 & 0.0177 & 1.0132 \\
\hline
\end{tabular}

Table 4. State variables of IEEE 30-bus system

\begin{tabular}{|c|c|c|c|c|c|c|}
\hline \multirow{2}{*}{$\begin{array}{c}\text { Bus } \\
\text { no }\end{array}$} & \multicolumn{2}{|c|}{$\begin{array}{c}\text { Case-1 } \\
\text { (Without TCSC) }\end{array}$} & $\begin{array}{c}\text { Case- 2 } \\
\text { (With TCSC base } \\
\text { load) }\end{array}$ & \multicolumn{2}{c|}{$\begin{array}{c}\text { Case-3 } \\
\text { With TCSC } \\
\text { critical load) }\end{array}$} \\
\cline { 2 - 7 } & L-index & Voltage & L-index & Voltage & L-index & Voltage \\
\hline 3 & 0.0009 & 1.0230 & 0.0009 & 1.0230 & 0.0017 & 1.0001 \\
\hline 4 & 0.0013 & 1.0190 & 0.0013 & 1.0190 & 0.0027 & 0.9968 \\
\hline 6 & 0.0000 & 1.0180 & 0.0000 & 1.0180 & 0.0000 & 1.0180 \\
\hline 7 & 0.0129 & 1.0040 & 0.0129 & 1.0040 & 0.0246 & 0.9916 \\
\hline 9 & 0.0000 & 1.0330 & 0.0000 & 1.0330 & 0.0000 & 1.0330 \\
\hline 10 & 0.0013 & 1.0130 & 0.0013 & 1.0130 & 0.0026 & 0.9910 \\
\hline 12 & 0.0050 & 1.0350 & 0.0050 & 1.0350 & 0.0091 & 1.0137 \\
\hline 14 & 0.0092 & 1.0180 & 0.0092 & 1.0180 & 0.0191 & 0.9864 \\
\hline 15 & 0.0045 & 1.0140 & 0.0045 & 1.0140 & 0.0093 & 0.9803 \\
\hline 16 & 0.0040 & 1.0190 & 0.0040 & 1.0190 & 0.0078 & 0.9940 \\
\hline 17 & 0.0063 & 1.0102 & 0.0063 & 1.0102 & 0.0118 & 0.9847 \\
\hline 18 & 0.0030 & 1.0000 & 0.0017 & 1.0017 & 0.0035 & 0.9639 \\
\hline 19 & 0.0051 & 0.9960 & 0.0024 & 0.9975 & 0.0050 & 0.9621 \\
\hline 20 & 0.0013 & 1.0000 & 0.0008 & 1.0006 & 0.0016 & 0.9652 \\
\hline 21 & 0.0036 & 1.0013 & 0.0036 & 1.0013 & 0.0067 & 0.9618 \\
\hline 22 & 0.0000 & 1.0015 & 0.0000 & 1.0015 & 0.0000 & 1.0015 \\
\hline 23 & 0.0046 & 0.9986 & 0.0046 & 0.9986 & 0.0091 & 0.9504 \\
\hline 24 & 0.0107 & 0.9864 & 0.0107 & 0.9864 & 0.0195 & 0.9512 \\
\hline 25 & 0.0000 & 0.9858 & 0.0000 & 0.9858 & 0.0000 & 09858 \\
\hline 26 & 0.0204 & 0.9677 & 0.0204 & 0.9677 & 0.0387 & 0.9512 \\
\hline 27 & 0.0000 & 0.9943 & 0.0000 & 0.9943 & 0.0000 & 0.9943 \\
\hline 28 & 0.0000 & 1.0153 & 0.0000 & 1.0153 & 0.0000 & 1.0153 \\
\hline 29 & 0.0066 & 0.9700 & 0.0033 & 0.9738 & 0.0034 & 0.9543 \\
\hline 30 & 0.0340 & 0.9610 & 0.0152 & 0.9626 & 0.0157 & 0.9509 \\
\hline
\end{tabular}


Table 5. Minimum Loss and Computational Time for IEEE 14-bus system

\begin{tabular}{|c|l|c|c|c|}
\hline Algorithm & Particulars & Case-1 & Case-2 & Case-3 \\
\hline GA & $\begin{array}{l}\text { Minimum } \\
\text { Loss (MW) }\end{array}$ & 13.406 & 12.600 & - \\
\hline NSPSO & $\begin{array}{l}\text { Minimum } \\
\text { Loss(MW) }\end{array}$ & 13.550 & 13.460 & - \\
\hline BF & $\begin{array}{l}\text { Minimum } \\
\text { Loss(MW) }\end{array}$ & 13.510 & 12.500 & 58.24 \\
\cline { 2 - 5 } & $\begin{array}{l}\text { Comp. } \\
\text { Time (sec) }\end{array}$ & 20 & 40 & 52 \\
\hline
\end{tabular}

Table 6. Minimum Loss and Computational Time for IEEE 30-bus system

\begin{tabular}{|c|l|c|c|c|}
\hline Algorithm & Particulars & Case-1 & Case-2 & Case-3 \\
\hline BF & $\begin{array}{l}\text { Minimum } \\
\text { Loss (MW) }\end{array}$ & 10.190 & 10.140 & 72.160 \\
\cline { 2 - 5 } & $\begin{array}{l}\text { Comp. } \\
\text { Time (sec) }\end{array}$ & 40 & 70 & 90 \\
\hline
\end{tabular}

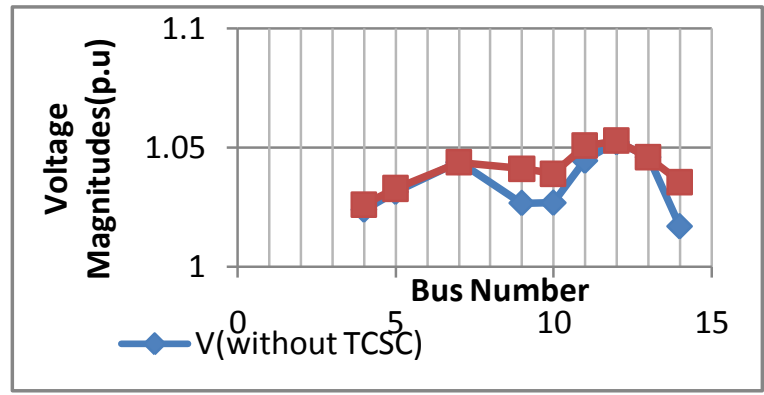

Figure 2. Bus Number Vs Voltage Magnitudes of IEEE 14-bus system

From the test results, it is clearly shown that the system voltage magnitudes have been improved, losses and L-index values are reduced with inclusion of TCSC between weakest load buses. With regard to IEEE 14-bus system, BF obtains $1 \%$ loss reduction compared to GA value reported [5] for the same test system and $7.7 \%$ loss reduction compared to NSPSO value reported [6],[7] for the same test system. L-index value of bus 9 decreased from 0.0129 to 0.0077 and voltage magnitude increased from 1.0267 to 1.0411, L-index value of bus 14 decreased from 0.0254 to 0.0098 and voltage magnitude increased from 1.0169 to 1.0355 (refer table 3). With regard to IEEE 30-bus system, L-index value of bus 29 decreased from 0.0066 to 0.0033 and voltage magnitude increased from 0.9700 to 0.9738 , L-index value of bus 30 decreased from 0.0340 to 0.0152 and voltage magnitude increased from 0.9610 to 0.9626 (refer table 4). For critical case, the system voltages get reduced below the minimum limit. When the TCSC included between buses 29 and 30, the voltage magnitude increased from 0.9194 to 0.9543 (at bus 29) and 0.8962 to 0.9509 (at bus 30). This shows the effectiveness of the proposed approach in minimizing the transmission line losses and voltage profile improvement simultaneously.

\section{CONCLUSION}

This paper made an attempt to find the optimal location and design values of TCSC for minimizing the losses, L-index and voltage profile improvement, which are taken as objective functions using bacterial foraging optimization algorithm. Results are presented for two test systems: the IEEE 14-bus and IEEE 30bus systems. The proposed algorithms used in this study were written in MATLAB software. The test results show that the bacterial foraging technique has the ability to improve voltage profile along with minimization of losses in the systems. The power loss occurring in the various branches and state variables of IEEE 14 bus and IEEE 30-bus systems are evaluated using BF based power flow analysis. From the results, it is concluded that the system performs better when the TCSC is connected. The state variables are improved and the transmission line losses are minimized than the results reported in the literature.

\section{REFERENCES}

[1] IEEE Publications, "Voltage Stability Analysis of Power Systems: Concepts, Analytical Tools and Industry Experience" IEEE Working Group on Voltage Stability, 1990.

[2] N.G.Hingorani, "Flexible AC Transmission Systems," IEEE Spectrum, April 1993, pp. 40-45.

[3] C.H. Liang, C.Y.Chung, K.P. Wong, X.Z.Duan, C.T.Tse, "Study of Differential Evolution for Optimal Reactive Power Dispatch", IET, Gen.Trans.Distribu. 1(2007), pp 253-260.

[4] H.Yoshida, K.Kawata, Y.Fukuyama, S.Takayama, Y.Nakinishi, "A Particle Swarm Optimization for Reactive Power and Voltage Control Considering Voltage Security Assessment", IEEE Transactions on Power Systems, 15(2000) pp 1232-1239.

[5] F.G.Bagriyanik, Z.E.Aygen and M.bagriyanik "Power Loss Minimization using Fuzzy Multi-Objective Formulation and Genetic Algorithm" IEEE Bolonga Power Tech Conference, June 23-26, Bolonga, Italy 2003.

[6] R.Benabid, M.Boudour M.A Abido "Optimal Location and Setting of SVC and TCSC devices using Non- Dominated Sorting Practical Swarm Optimization" Journal of Electrical Power System Research, 2009 pp 1668- 1677.

[7] Kevin M Passino "Biomimicry of Bacterial Foraging for Distributed Optimization and Control", IEEE Control Systems Magazine, June 2002.

[8] M.Gitizadeh, M.kalantar "A Novel Approach for Optimum Allocation of FACTS Devices using Multi -Objective Function" Journal of Energy Conversion and Management 2009, pp 682690.

[9] M.Senthil Kumar, Dr.P.Renuga, D.Prasad "A Bacterial Foraging Based Multi-Objective Reactive Power Planning" International Journal of Applied Engineering Research Newdelhi Vol 4, No 8, 2009 pp 1413-1422.

[10] Antonino Augugliaro, Luigi Dusonchet, Salvatore favuzza And Eleonora Riva Sanseverino "Voltage Regulation and Power Losses Minimization in Automated Distribution Networks by an Evolutionary Multi objective Approach" IEEE Transactions on Power Systems, vol 19 no.3 Aug 2004 pp 1516-1527.

[11] P.K.Modi, S.P.Singh, J.D.Sharma "Fuzzy Neural Network Based Voltage Stability Evaluation of Power Systems with SVC" Journal of Applied Soft Computing,2008 pp 657- 665. 
[12] Nimit Boonpiron, Kitti Paitonwattanakiji, "Static Voltage Stability Enhancement Using FACTS", IEEE Transactions on Power Systems, vol.3, 1997.

[13] S.Durairaj, Devaraj and P.S.Kannan, "Improved Genetic Algorithm Approach for Multi- Objective Contingency Constrained Reactive Power Planning", IEEE Indicon 2005 Conference, Chennai, Dec 2005.
[14] Garng. M.Huang, Nirmal Kumar C Nair "Incorporating TCSC into the Voltage Stability Constrained OPF Formulation" IEEE Power Engineering Society Summer Meeting Vol no 3 2002, pp 1547-1552, 